\title{
XII. On the natural zero, according to Fahrenheit's scale
}

\section{Sir George Cayley Bart.}

To cite this article: Sir George Cayley Bart. (1829) XII. On the natural zero, according to Fahrenheit's scale, Philosophical Magazine Series 2, 5:26, 88-91, DOI: $10.1080 / 14786442908674926$

To link to this article: http://dx.doi.org/10.1080/14786442908674926

里 Published online: 10 Jul 2009.

Submit your article to this journal $[\pi$

Џ Article views: 3

Q View related articles $₫$ 
XII. On the Natural Zero, according to Fahrenheit's Scale. By Sir. Georfre CaYLeY, Bart.

To the Editors of the Philosophical Magazine and Annals. Gentlemen,

3, Rue Castiglione, Paris, Dec. 20, 1828.

I SEND you the following considerations respecting the natural zero, which though perhaps not perfectly conclusive, yet lead to a strong probability that the point of absolute privation of transferable caloric, as respects temperature, takes place at 4.48 degrees of Fahrenheit's scale below his $0^{\circ}$, taking such degrees of this scale as range between $32^{\circ}$ and $212^{\circ}$ as the standard, and leaving the more refined inquiry as to their inequality at present out of the question, though fully admitting that the zero I have named must hereafter be regulated by the final result of that inquiry.

It appears that hydrogen gas at a mean temperature is about 11,242 times lighter than water, and also that it can exist as a component part of water: hence if it were mechanically condensed 448 times, when of the temperature of $32^{\circ}$, and supposing the particles to be as dense as water, there would still remain twenty-two-fold more space unoccupied than occupied by them; hence there would be no reason to suspect that their chemical relation to each other would be altered or deranged by this condensation. If 10,000 cubic inches of hydrogen gas under mean atmospheric pressure at a temperature of $32^{\circ}$, be elevated to the temperature of $212^{\circ}$, it will be expanded to 13,744 cubic inches, and all the experiments that have been made on the subject prove, that the expansion or contraction of all the gases at a temperature of $32^{\circ}$ proceed in perfect uniformity with the addition or privation of caloric as measured by the thermometer, giving one 480th part of the whole bulk for each degree of Fahrenheit's scale. As this is the property of all the permanent gases, differing so widely as they do in their specific gravities, chemical qualities, and in their specific relation even to caloric itself, it seems to point out that in these aëriform fluids, when chemical attraction is in their own nature overcome, the expansion becomes the actual measure of the transferable caloric they contain, in that relation to heat we call temperature. In all these gases if we could reduce the temperature $480^{\circ}$ below $32^{\circ}$, all bulk, as connected with temperature, would cease; the particles would become contiguous, and deprived of all elasticity. The effect seems the measure of the cause; they originate and cease together. It may be argued against this theory, that steam and the vapours 
of different tluids, as those of æther, alcohol, \&c. are found to expand with equal uniformity by equal additions of temperature; but that each vapour has its own grade of elasticity: and hence that privation of caloric at which elasticity would cease, differs in each; chemical affinity between the particles in these cases seems to exert to a certain extent a contuolling power over caloric, and to modify its action. There is also a chemical combination of caloric with these fluid substances when they change to a state of vapour, which may materially affect their relation to transferable caloric : thus steam of $212^{\circ}$ cantains about $960^{\circ}$ degrees of caloric in chemical union, which does not affect its temperature. It depends upon the degree of pressure the water is exposed to, at what temperature it will rise into vapour and commenee this vast but imperceptible absorption of caloric. An additional pressure of three pounds per square inch, requiring about ten degrees more temperature before vaporization commences; hence the power, whatever it be, by which the caloric enters into chemical union at $202^{\circ}$, is three pounds per square inch less forcible than at $212^{\circ}$, and six pounds less than at $222^{\circ}$, the whole power at $212^{\circ}$ being equal to about fifteen pounds per square inch. The same ratio exists as to this power in alcohol at $176^{\circ}$, and in ether at about $98^{\circ}$; in the former 38 degrees below the boiling point of water, and in the latter $128^{\circ}$. The expansive power arising from temperature.in these cases is evidently modified by the chemical affinities of these substances, as is rendered more evident by the circumstance that æether, the boiling point of which is so much below that of alcohol, freezes at $-46^{\circ}$; whereas alcohol has been exposed to a temperature of $-9 l^{\circ}$ without freezing; and it rests on one authority only that it can be congealed at all, and that at a temperature of $-110^{\circ}$. The striking circumstance with respect to the permanent gases is, that they all agree as to the privation of temperature at which they would cease to be elastic. In their chemical formation they seem to have embodied permanently as much caloric as neutralizes all attraction between their particles; and hence every addition of temperature from the natural zero exhibits an expansion, or a force equivalent, if unrestrained, to generate expansion.

When we see that a few pounds pressure per square inch has so much effect upon fluids when upon the point of rising into vapour, and contemplate the power which the particles of water exert when passing into the state of ice, so as exen to split bomb-shells and cannon,-it seems very probable that in vapours, the effects of temperature are disturbed by counteracting forces, but that they have their full and undisturbed in-

New Series. Vol. 5. No. 26. Feb. $1829 . \quad$ N fluence 
fluence with perfect uniformity in the gases; and that all these point to $480^{\circ}$ below $32^{\circ}$, or $448^{\circ}$ below $0^{\circ}$, as their temperature of non-elasticity or privation of all transferable caloric. There is an apparent contradiction to this hypothesis in the circumstance that common air, when suddenly condensed seventy or eighty times, kindles the tinder called amadou, and fires gunpowder, \&c.; but as the capacity of bodies for caloric is in some inverse ratio of their density, much heat must be evolved by such a great increase of density; even a red heat is soon excited, by the condensation of soft iron under the hammer to the extent of only 1-33rd part of its bulk; and hence the fact is sufficiently accounted for, and is a case quite distinct from the caloric of temperature.

For the purpose of showing how small a proportion there is between the 4.48 degrees $I$ have assumed as beyond the zero of Fahrenheit, and the absolute quantity of caloric embodied by some of the permanent gases, let two volumes of hydrogen gas be condensed 448 times when of the temperature of $0^{\circ}$ Fahr.; and as this is the proper proportion to generate water by combustion, supposing the particles to be each of the density of water, they would not be reduced to contact by this degree of condensation, but would have about sixteen times more space unoccupied than occupied : hence their chemical constitution would not be endangered unless done too suddenly, so as to evolve caloric enough to ignite them. If this mixture were reduced to the temperature of $448^{\circ}$ below $0^{\circ}$, the particles would then be in contact, and require no pressure to keep them so. We may probably assume without much error, that from the reduced capacity as to caloric, as much of it will have escaped, from this cause, as would raise the temperature of the condensed mass about 900 or 1000 degrees, and at the same time it will have lost by temperature $448^{\circ}$ : thus it might be said that 1448 degrees of heat are parted with by the gases before they reach the natural zero; but it is obvious that the $448^{\circ}$ only are due to the account of thermometrical temperature; the other to a separate and distinct cause; viz. the diminution of capacity with respect to the caloric permanently embodied in these gases by chemical combination. I shall quote from some experiments by Count Rumford, on the caloric generated by combustion, that one pound of hydrogen gas used as fuel will raise 410 pounds of water from $32^{\circ}$ to $212^{\circ}$, or $180^{\circ}$; (this estimate may not perhaps be very correct, but is sufficient for my purpose) one pound of hydrogen gas requires eight pounds of oxygen gas to saturate it in the formation of steam or water by combustion; and hence the whole caloric, which in the other instance was applied to 410 pounds of water, is during the combustion 
combustion applied to the nine pounds of steam or water generated; and therefore its temperature considered as water, would be raised as much more than $180^{\circ}$ as 410 exceeds $9\left(\frac{41}{9} 0 \times 180\right)$, or 8200 of Fahrenheit's scale. If we knew with more accuracy the proportionate capacities of water and of these gases, we might thus tolerably ascertain the actual ratio between that caloric which is chemically combined and which seems to constitute the gaseous state, that which is lost by temperature, and that which is lost by reduced capacity. If we assume that, when these two gases are reduced to the contact of particles by a temperature of -448 , they have the same capacity for caloric as water, and that in the condensation they have lost 1000 degrees by reduced capacity, we shall have the proportion of that which is moveable by both causes, when compared with that chemically combined and permanent, as 1448 to 8200 , or nearly as 1 to $5 \cdot 7$. It is of great importance to ascertain the actual commencement of our scale of temperature, as it would lead to an accurate knowledge of what certain determinate quantities of caloric can effect, and it would come measureable, as the other constituents of compound bodies are. It is very probable that caloric will be found to combine in distinct doses when it enters into those chemical unions not affecting temperature. If we assume - 44.8 as the true zero, and assume $20^{\circ}$ as a dose of caloric, the history of water in its relation to it would stand thus: We should have twenty-four doses or $480^{\circ}$ of heat in ice at $32^{\circ}$; an addition of seven doses, or $140^{\circ}$, melts it to water; nine doses, or $180^{\circ}$, brings it to the boiling point under atmospheric pressure, and forty-eight doses more, or $960^{\circ}$, generates steam at $212^{\circ}$.

I am, Gentlemen, yours, \&c.

Geo. Cayley.

XIII. On Interpolation.

(From Prof. Encke's Astronom. Jahrbuch for 1830, p. 265.)

[Concluded from p. 36.]

FOR calculation it is most convenient to correct successively each of the difference-quantities by the following one, and separating the common factors to write the formula as follows:

$$
\begin{aligned}
\mathrm{X}=\mathrm{A}+(x-a)\{[a b] & +x-b\left\{\left[a_{a} a b\right]\right. \\
& \left.+x-a_{1}\left\{\left[a_{1} a b b_{1}\right] \ldots\right\}\right\}
\end{aligned}
$$

The factors are here used in the following order: $\left(x-b_{n}\right),\left(x-a_{n}\right),\left(x-b_{n-1}\right), x-a_{n-1} \cdots\left(x-a_{1}\right),(x-b),(x-a)$.

If we proceed, therefore, from $x$, and then first take the $\mathrm{N} 2$ nearest 